Congreso Internacional: «Miradas recíprocas : Perú y Francia (1713-1959). Viajeros escritores y

\title{
analistas»
}

Lima, 4-6 de septiembre de 2014

\section{Mónica Cárdenas}

\section{(2) OpenEdition}

12 Journals

\section{Edición electrónica}

URL: http://journals.openedition.org/bifea/6008

DOI: $10.4000 /$ bifea.6008

ISSN: 2076-5827

Editor

Institut Français d'Études Andines

\section{Edición impresa}

Fecha de publicación: 1 diciembre 2014

Paginación: 647-650

ISSN: 0303-7495

\section{Referencia electrónica}

Mónica Cárdenas, « Congreso Internacional: «Miradas recíprocas : Perú y Francia (1713-1959).

Viajeros escritores y analistas» », Bulletin de l'Institut français d'études andines [En línea], 43 (3) | 2014,

Publicado el 08 diciembre 2014, consultado el 07 noviembre 2020. URL : http://

journals.openedition.org/bifea/6008; DOI : https://doi.org/10.4000/bifea.6008

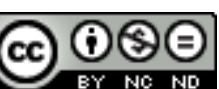

Les contenus du Bulletin de l'Institut français d'études andines sont mis à disposition selon les termes de la licence Creative Commons Attribution - Pas d'Utilisation Commerciale - Pas de Modification 4.0 International. 


\section{Eventos}

\section{CONGRESO INTERNACIONAL «MIRADAS RECÍPROCAS: PERÚ Y FRANCIA (1713- 1959). VIAJEROS ESCRITORES Y ANALISTAS»}

Lima, 4-6 de septiembre de 2014

El evento se inauguró el 4 de septiembre en el Instituto Porras Barrenechea, se trasladó el viernes 5 a las instalaciones del Instituto Riva-Agüero y se clausuró el sábado 6 en la Casa de la Literatura Peruana.

La organización y coordinación científica estuvo a cargo de los profesores Isabelle Tauzin Castellanos (Université Bordeaux Montaigne) y Oswaldo Holguín Callo (PUCP). El evento se hizo posible gracias al auspicio de instituciones como el equipo de investigación Ameriber (Bordeaux, Francia), la Embajada de Francia, el IFEA (Umifre 17, MAEDI-CNRS, USR 3337 América Latina) y la PUCP.

Tras la convocatoria, se recibieron numerosas propuestas, de las cuales el comité científico seleccionó treinta trabajos de investigadores procedentes de universidades e instituciones francesas (Université de Paris Sorbonne Nouvelle, Université Bordeaux-Montaigne, Archives Nationales/Centre EREA, CNRS, Université de Paris Ouest Nanterre la Défense), peruanas (Pontificia Universidad Católica del Perú, Archivo General de la Nación, Seminario de Historia Rural Andina, Universidad Nacional Mayor de San Marcos, Universidad de San Martín de Porres, Universidad Ricardo Palma, Universidad Católica Sedes Sapientiae, Universidad de Lima, Universidad Católica San Pablo), latinoamericanas (Universidad Nacional de Quilmes-Argentina, Instituto Nacional de Antropología e Historia/UNAM-México, Universidad Externado de Colombia/IFEA-Bogotá, Asociación de Historia Marítima y Naval Iberoamericana) y estadounidense (University of Notre Dame).

Todos los trabajos aceptados fueron presentados en el lugar y el momento previstos lo que contribuyó al desarrollo ordenado y coherente de la temática planteada. Los expositores comunicaron lo esencial de sus investigaciones a lo largo de once mesas. Estas giraron principalmente en torno a tres grandes ejes temáticos. 
En primer lugar, los aportes de los viajeros franceses a la historia y la representación del Perú. Para ello contamos con los trabajos de investigadores como: Isabelle TauzinCastellanos, Pascal Riviale, Catherine Heymann, Bernard Lavallé, Javier Protzel y Vera Alvizuri. En esta sección destacamos las reflexiones acerca del viaje del marino Gabriel Lafond de Lurcy entre 1821 y 1841. Sus observaciones no solo son una fuente para conocer costumbres, eventos políticos y formas de vida de la época, sino que nos ayuda a problematizar visiones tradicionales de la historia como el rol de per-

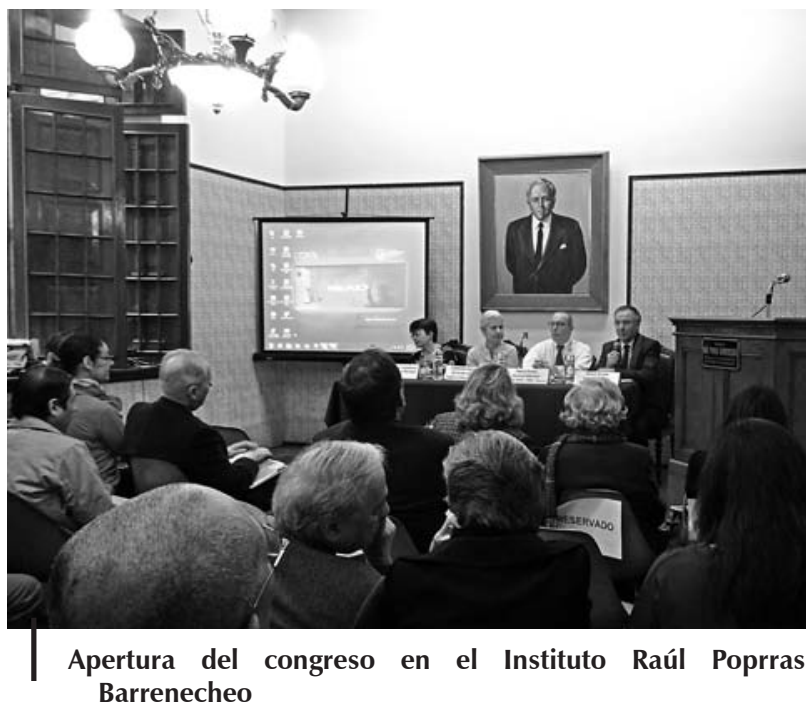
sonajes emblemáticos —la tapada, entre ellos - dentro del imaginario limeño. Años más tarde, Olivier Ordinaire recorre tierras peruanas (1889-1902) imponiendo a sus escritos una descripción de imágenes, percepciones y sensorialidad propias.

También se presentaron interesantes investigaciones sobre dos viajeros del siglo XVII. Los escritos de Amadeo Frézier quien opuso su visión y sus descubrimientos al trabajo que años atrás había realizado Luis Feuillée sobre la botánica, zoología, ciencias médicas y sociales para las cuales tomó en cuenta elementos de la historia prehispánica y costumbres locales.

Pudimos apreciar, asimismo, un vasto trabajo sobre los viajeros franceses a la Amazonía peruana desde el siglo XVIII hasta el XXI. Se hizo hincapié en la periodización, los tópicos, los medios, las formas y la evolución de las ideologías de dichos exploradores. Por otro lado, se discutió acerca de las implicaciones deontológicas en el trabajo antropológico del fundador del Instituto Francés de Estudios Andinos, Jehan Vellard, a mediados del siglo XX. El estudio de la política de lo que se denomina el 'andinismo francés' otorga el contexto para el estudio del caso de la adopción de una niña guayaqui.

En segundo lugar, se trató acerca de la influencia francesa en la historia, el pensamiento y la cultura peruana. En esta sección contamos con los aportes de investigadores como Jorge Ortiz, Ricardo Melgar, Elodie Vaudry, Pedro Díaz, Oswaldo Holguín y Margarita Guerra. Así, por ejemplo, pudimos conocer el compromiso de Elena Izcue en la promoción de las artes tradicionales del Perú que la llevó a establecer múltiples vínculos entre el museo Larco Herrera de Lima y el de etnografía del Trocadero de París y a construir una teatralización de las creaciones precolombinas. Por otro lado, se trató acerca de relación entre el Apra y el exilio francés. Así, particularmente, en el París de 1926, se conformó un conjunto musical procedente del sur andino que sirvió como vehículo de 
propaganda y estrategia de supervivencia gracias a las redes de paisanaje regional que se extendieron del Perú hacia Francia.

En este interesante proceso de préstamos culturales, se presentaron notables aportes sobre dos escritores fundamentales. Ventura García Calderón, nacido y muerto en París, fue el representante y embajador de la literatura latinoamericanas en París. En este proceso de construcción de su obra y de una identidad literaria peruana en París, presentó y admiró los escritos de Ricardo Palma. Sobre este, se discutió acerca de los usos y formas de la cultura francesa incluidas en la Lima que evocan sus escritos.

En tercer lugar, hemos invitado a la reflexión sobre los discursos literarios y las representaciones que resultaron del intercambio vivencial y cultural entre Francia y Perú. Para ello contamos con los trabajos de investigadores como: Margarita Pierini, Sara Beatriz Guadia, Mónica Cárdenas, Marcel Velázquez y Vanesa Miseres.

De esta manera, se presentaron los trabajos acerca de dos creadores híbridos: Nicanor della Rocca de Vergalo y César Vallejo. El primero con gran parte de su obra escrita en francés, y casi desconocido por la crítica peruana, pretendió una transformación del verso y la poesía en general a partir del contacto con los simbolistas franceses. Por otro lado, a pesar de que César Vallejo mantuvo la firmeza de escribir siempre en español, su obra estuvo en constante evolución y, sobre todo en sus crónicas, se refleja la necesidad de darle un lugar importante a la realidad de los países latinoamericanos en la prensa y la cultura francesas.

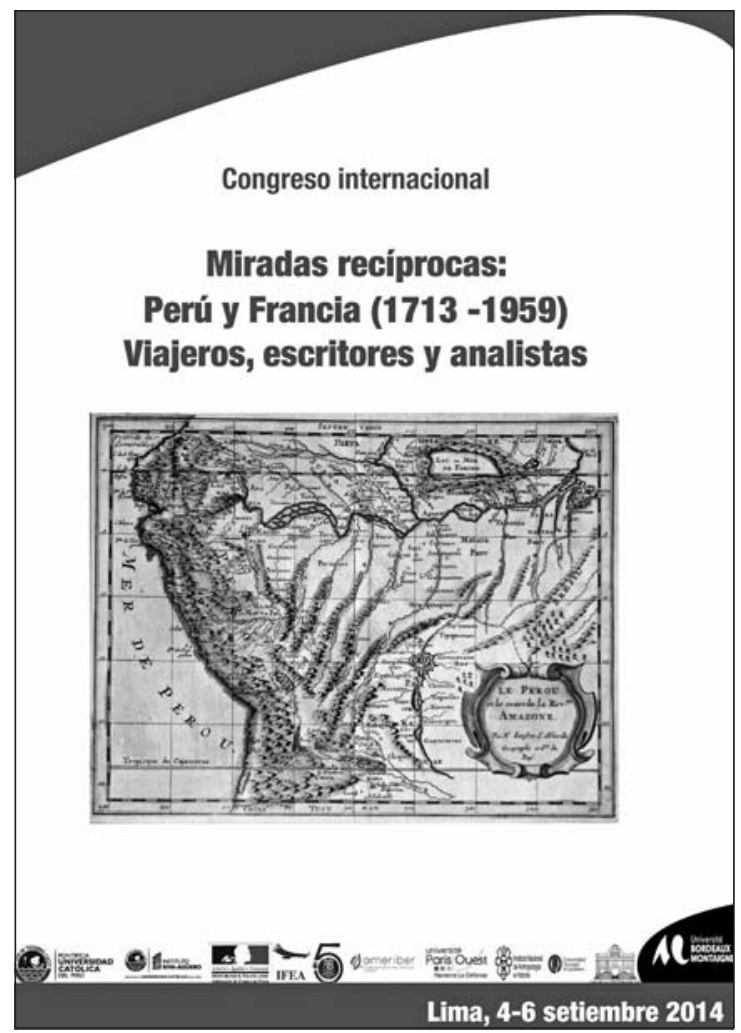

Los trabajos sobre Flora Tristan comprendieron el análisis de estrategias discursivas y formas de narrar subordinadas a objetivos políticos en Peregrinaciones de una paria. Desde otra perspectiva, se hizo hincapié en el testimonio de la cultura arequipeña y limeña de la época que nos deja la lectura del importante libro de viajes de la autora. También se reflexionó acerca de su proyecto auto-ficcional a partir de los nuevos códigos que proporciona su única novela (aún no traducida al español) Méphis. El análisis de los libros testimoniales de Adriana Verneuil de González Prada, Juan de Arona y Aurora Cáceres permitió abrir una reflexión acerca de las formas de la autoficción cuando estas se encuentran al servicio de la narración de un espacio extranjero. 
Con el propósito de promover y enriquecer el diálogo académico, fueron convocados reconocidos investigadores peruanos como moderadores de cada una de las mesas. Entre ellos: Carlos Contreras, Ricardo Silva Santisteban, Juan Luis Orrego, Gérard Borras, Alberto Varillas. De esta manera, gracias a las preguntas del público, se llevaron a cabo interesantes debates durante los tres días que duró el evento.

Una de las actividades propuestas fue la presentación de libros al final de la primera jornada. En este espacio, fueron comentados por sus propios autores: Une vie dans les Andes: le journal de Théodore Ber (1864-1896) de Pascal Riviale, Mujeres de Amauta de Sara Beatriz Guardia, Escritoras latinoamericanas del siglo XX de Margarita Pierini y la revista literaria Lucerna de Julio Isla. 